Discussion Paper No. 04-80

\title{
Price Structure in Two-sided Markets: Evidence from the Magazine Industry?
}

Ulrich Kaiser and Julian Wright

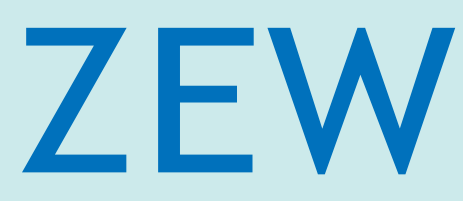

Zentrum für Europäische Wirtschaftsforschung $\mathrm{GmbH}$ Centre for European Economic Research 
Discussion Paper No. 04-80

\title{
Price Structure in Two-sided Markets: Evidence from the Magazine Industry?
}

\author{
Ulrich Kaiser and Julian Wright
}

Download this ZEW Discussion Paper from our ftp server:

ftp://ftp.zew.de/pub/zew-docs/dp/dp0480.pdf

Die Discussion Papers dienen einer möglichst schnellen Verbreitung von neueren Forschungsarbeiten des ZEW. Die Beiträge liegen in alleiniger Verantwortung der Autoren und stellen nicht notwendigerweise die Meinung des ZEW dar.

Discussion Papers are intended to make results of ZEW research promptly available to other economists in order to encourage discussion and suggestions for revisions. The authors are solely responsible for the contents which do not necessarily represent the opinion of the ZEW. 


\section{Non-technical summary}

This paper generates estimates of the parameters of a two-sided market model of competing magazine publishers. We use panel data from the German magazine industry that spans the period 1972 to 2003. A key question of this paper is what is the markup over marginal cost charged to advertisers relative to that charged to readers? Our results are consistent with the conventional wisdom that advertisers value readers more than readers value advertisements, and that as a result, magazines "subsidize" cover prices, and make their profit from advertisers.

We apply our estimated model to consider cross-market comparative statics. Reflecting that advertisers value readers more than readers value advertisers, we find an increase in reader demand results in an increase in ad rates while an increase in advertising demand results in a decrease in cover prices. This asymmetric result reflects the incentive to subsidize readers to attract additional advertisers when the advertising side becomes more lucrative, but not vice-versa. Rather, if demand on the reader side increases (or costs fall), our estimated model implies there is an incentive to increase ad rates so as exploit the resulting increased demand on the advertising side. 


\title{
Price structure in two-sided markets: Evidence from the magazine industry ${ }^{\S}$
}

\author{
UlRICH Kaiser* and Julian Wright**
}

\begin{abstract}
We present and estimate a model of competition in a two-sided market: the market for magazine readership and advertising. Using data on magazines in Germany, we find evidence that magazines have properties of two-sided markets. The results are consistent with the perception that prices for readers are "subsidized" and magazines make most of their money from advertisers. Consistent with advertisers valuing readers more than readers value advertisements, our results imply that higher demand or lower costs on the reader side increase ad rates, but that higher demand or lower costs on the advertising side decrease cover prices.
\end{abstract}

\footnotetext{
${ }^{\S}$ We would like to thank Hans Christian Kongsted, Armin Schmutzler, Christian Schultz, and Rainer Winkelmann, as well as other seminar participants from the University of Copenhagen, the University of Zurich and the 2004 meeting of the German Economic Association for their helpful suggestions. We are particularly grateful for the detailed comments we received from two anonymous referees.

${ }^{*}$ Corresponding author: University of Southern Denmark at Odense, Dept. of Economics, Campusvej 55, 5230 Odense M, Denmark; email: uka@sam.sdu.dk; internet: http://www.sam.sdu.dk/staff/uka; core member, Centre for Economic and Business Research, Copenhagen; and permanent research professor, Centre for European Economic Research, Mannheim.

** Department of Economics, National University of Singapore. AS2 Level 6, 1 Arts Link, Singapore 117570; email: jwright@nus.edu.sg; internet: http://profile.nus.edu.sg/fass/ecsjkdw/.
} 


\section{Introduction}

Many markets where network externalities are important are, in fact, two-sided markets. Two-sided markets have the property that there are two distinct types of users, each of which wishes to interact on a common platform, and in which the structure of prices between the two sides (rather than just the total level of prices) matters. ${ }^{1}$ Some common examples include directory services such as classifieds and Yellow Pages; matching markets such as employment websites, dating agencies; media markets such as magazines, newspapers and Internet Portals; and trading posts such as auctions, B2B markets, and shopping malls.

A key question arising in two-sided markets is how does the platform price to each type of user? Is one side of the market "subsidized" in order to attract the other? Armstrong (2004), Caillaud and Jullien (2003), and Rochet and Tirole (2003) each provide theoretical frameworks of two-sided markets to explain how the structure of prices is determined. This paper takes one such framework and uses it to explore magazine markets in Germany.

The model considered is based on an adapted version of Armstrong's model with exclusive intermediation. In the model, two differentiated platforms set joining fees, and users on each side exclusively subscribe to one of the platforms. Advertisers value the number of readers of the magazine and readers value the number of ads in the magazine. In addition, we allow readers to value the amount of content in the magazine. A magazine chooses a cover price, an advertising price and the amount of content to produce in order to maximize its profits, given the prices and content choice of the rival magazine. We derive the implied demand system from such a model and estimate it using data on magazines from Germany. The model then provides a link between the estimated demand parameters and the structure of price-cost margins across readers and advertisers, as well as other variables of interest.

There is a large existing empirical literature on media markets that allows for interrelated demands between readers and advertisers. Dewenter (2003) provides a survey. Much of this literature focuses on the newspaper industry, and is concerned with estimating the effects of concentration (Reddaway, 1963 and Thompson, 1984), the existence of economies of scale (Rosse, 1967, 1970; Bucklin et al. 1989); and showing the existence of two-way network effects (Dertouzos and Trautman, 1990). ${ }^{2}$ Typically, newspapers are assumed to be monopolistic with respect to the readership side. As a result, unlike this paper, the literature does not consider how the structure of prices emerges from competition between two platforms that strategically set prices to each side to take into account interrelated demands.

\footnotetext{
${ }^{1}$ See Rochet and Tirole (2004) for a more precise definition. See also Evans (2003a, 2003b).

${ }^{2}$ There is also a sizeable empirical literature testing for network effects in one-sided market settings, including amongst others, Gandal et al. (2000) who consider the case of compact disk players, and Saloner and Shepard (1995) who consider the case of Automated Teller Machines. The issue addressed in this paper, that of the structure of prices between each side of the market, does not arise in this literature.
} 
More recently, Rysman (2004) estimates a two-sided model of Yellow Pages that allows for such competition. However, in the case of Yellow Pages, only one side (the advertising side) faces fees. This means Rysman cannot consider the determination of the structure of prices with his data. Moreover, he assumes quantity setting platforms to avoid the fixed point problem that arises in a price setting game with network effects. This motivates our focus on magazines, as well as our particular model specification which allows us to study the structure of price-cost margins with estimates of the demand system alone.

Magazines, like newspapers, typically involve both readers and advertisers being charged. Moreover, unlike other examples of two-sided markets where both sides are charged (for example, payment cards and video game platforms), magazines do not involve widespread multihoming on either side, and so provide a better match to the model of exclusive platform competition considered by Armstrong. ${ }^{3}$ The nature of magazine pricing also matches the assumption made in this framework, in that users on each side pay to "join" the platform (rather than based on transactions made between the two types of users), and that there are markets with only two magazines competing.

The parameters of the model are estimated using an unbalanced panel of nine distinct two-magazine groups in Germany during the period 1972-2003. We illustrate how the estimated parameters can then be used to determine the size of the network effects running in each direction (how much readers value ads, and how much advertisers value readers), and how the structure of the price-cost margins and cross-market comparative static results reflect asymmetries across the two sides of the market.

The rest of the paper proceeds as follows. Section 2 presents the model of a twosided market that we estimate. Section 3 describes the data, while Section 4 describes our empirical specification. Results and implications are presented in Section 5. Finally, Section 6 provides some concluding comments.

\section{A model of magazines as a two-sided market}

We adapt the generic model of two-sided exclusive platform intermediation developed by Armstrong (2004, Section 4) to the magazine market. His model is one in which two platforms compete. Competition on each side of the market is modelled in a differentiated Bertrand fashion, with demands derived from a Hotelling specification. The complication is that each group values the number of users of the opposite group on the same platform. We extend this model in a straightforward way by noting magazines provide three types of services. They provide content for readers, ads which allow readers to find out about products (possibly) of interest, and an advertising outlet which provides firms with a way to inform readers about their products. Specifically, we allow subscribers' utility to also depend on the number of content pages in the magazine, and let magazine publishers

\footnotetext{
${ }^{3}$ For our sample, most readers do not buy both rival magazines and most firms do not advertise in both rival magazines. We provide evidence for this in Appendix B.
} 
choose content pages as an additional strategic variable.

The Hotelling specification gives rise to a particular specification of demand ${ }^{4}$

$$
\begin{aligned}
s_{1} & =\frac{1}{2}+b+\gamma\left(N_{1}^{a}-N_{2}^{a}\right)+\psi\left(N_{1}^{c}-N_{2}^{c}\right)-\beta\left(p_{1}-p_{2}\right)+\varepsilon_{1}-\varepsilon_{2} \\
s_{2} & =1-s_{1} \\
n_{1}^{a} & =\frac{1}{2}+\phi+\rho\left(S_{1}-S_{2}\right)-\eta\left(a_{1}-a_{2}\right)+\xi_{1}-\xi_{2} \\
n_{2}^{a} & =1-n_{1}^{a},
\end{aligned}
$$

where $s_{i}=S_{i} / S$ is the share of readers of magazine $i$ out of a total of $S$ readers for both magazines, and $n_{i}^{a}=N_{i}^{a} / N$ is the share of ads in magazine $i$ out of a total of $N$ ads in both magazines. The amount of content in magazine $i$ is captured by $N_{i}^{c}$, while $p_{i}$ is the price per copy that magazine $i$ charges readers and $a_{i}$ is the price per ad that magazine $i$ charges advertisers. The error terms $\varepsilon_{i}$ and $\xi_{i}$ capture unobservable (mean zero) components to the utilities of each group from each magazine, while the parameters $b$ and $\phi$ capture unobservable asymmetries in preference between the two magazines. The parameters measuring the strength of network effects in each direction are $\gamma$ and $\rho$, while the intensity of competition (or the inverse of the extent of product differentiation) is measured by the parameters $\beta$ and $\eta$.

These share equations assume all agents choose one of the magazines exclusively. In appendix B, we show how the model here can be reinterpreted to allow for the fact some agents choose both magazines (multihome). We also show that such multihoming is not widespread in the markets we consider. Both findings provide support for the approach we take.

The profits of the publisher of magazine $i$ are then

$$
\Pi_{i}=\left(p_{i}-f_{i}\right) S_{i}+\left(a_{i}-c_{i}\right) N_{i}^{a}-d_{i}\left(N_{i}^{c}\right)^{2}-F_{i},
$$

where $f_{i}$ is the cost of printing and distributing the magazine per copy sold ${ }^{5}, c_{i}$ is the cost of producing a single ad for magazine $i, d_{i}$ is the cost of producing a page of content (that also varies between the magazines), and $F_{i}$ is other fixed costs of operations. Variable cost that are associated with producing ads include liasing with clients on each ad. Note that content is costly to produce. It only contributes to profit to the extent it causes an increase in circulation, and indirectly ad revenue. Moreover, content is assumed to have increasing marginal costs (it is more and more expensive to get additional interesting stories and material for each issue).

Each magazine sets $p_{i}, a_{i}$ and $N_{i}^{c}$ to maximize its profits, given the choices of its rival. After observing the choice of these variables, consumers (readers) decide which

\footnotetext{
${ }^{4}$ Appendix A provides the derivation of this demand specification.

${ }^{5}$ In the case the magazines are sold via subscription, this includes the cost of postage and handling, while if the magazines are sold via kiosks, newsstands and bookstores, then this includes the payment that these retailers require. Unlike the case in the United States, in Germany most subscription prices are quite similar to those offered at the newsstands (Kaiser, 2003).
} 
magazine to buy and firms (advertisers) decide which magazine to advertise in. Rational expectations are assumed, so readers and advertisers work out how many of each type will subscribe to each magazine using the above model when making their own decision. Provided network benefits are not explosive (which requires $\rho \gamma N S<1 / 4$, a condition that will be checked empirically), rational expectations imply unique demands, which are the simultaneous solutions to (1)-(4).

Solving for unique demands, substituting these into (5) for $i=1$ and 2, and taking the first order conditions, we can express the equilibrium conditions for both magazines as:

$$
\begin{aligned}
p_{i}-f_{i} & =\frac{s_{i}}{\beta}-\frac{2 \rho N_{i}^{a}}{\eta} \\
a_{i}-c_{i} & =\frac{n_{i}^{a}}{\eta}-\frac{2 \gamma S_{i}}{\beta} \\
N_{i}^{c} & =\frac{\psi S_{i}}{2 d_{i} \beta} .
\end{aligned}
$$

Equilibrium cover prices are marked up above cost to the extent of product differentiation on the readership side, but discounted to reflect the externality generated on the advertising side of the market from a magazine attracting more readers. In equilibrium, the magazines discount cover prices to attract more readers, thereby attracting more advertisers. This effect is increasing in the extent to which advertisers value readers and in the number of firms wanting to place ads in magazine $i$, and is decreasing in the sensitivity of a magazine's ad demand to its ad rate (if ad demand is very sensitive to ad rates, then lowering ad rates becomes a cheaper way for magazines to generate additional advertisers rather than subsidizing readers).

Likewise, equilibrium ad rates are marked up above cost to the extent of product differentiation on the advertisers' side, but are discounted to reflect the externality generated on the readership side of the market from a magazine attracting more ads. If attracting more ads allows a magazine to attract more readers, then the magazine will take this into account when pricing ads. Specifically, magazines will discount the price of ads by the extent to which readers value ads and by the number of readers of magazine $i$, but will increase ad prices when readers are more sensitive to a magazine's cover price (if readers are very sensitive to cover prices, then lowering cover prices is a cheaper way for magazines to generate additional readers rather than discounting the price of ads).

For both cover prices and ad prices, the markup above cost is higher the higher the respective equilibrium market shares reflecting the fact that if a magazine is preferred by readers or advertisers (has a positive value of $b$ or $\phi$ ), this will cause that magazine to price higher to exploit its more 'loyal' customer base.

Finally, the level of content is increasing in the amount readers value content and in the total number of magazine readers (since then each page of content generates more revenue), but is decreasing in the cost of producing content and in the sensitivity of magazine readers' demand to the cover price (if readers are very sensitive to cover prices, 
then lowering cover prices is a cheaper way for magazines to generate additional readers rather than producing additional content).

Our estimation approach is to estimate the share equations (1) and (3) so as to obtain estimates of the parameters $\gamma, \psi, \beta, \rho$, and $\eta$. These can then be used to solve for the equilibrium price-cost margins (6) and (7), which are the expressions of central interest. This avoids the need to estimate costs through the first order conditions, which leads to imprecise estimates of all parameters, given the interrelated nature of the two sides of the market and only limited data availability. This illustrates the value of using the linear demand specification in (1)-(4). The Hotelling assumptions on consumer behavior and the assumed linear network benefits, when combined with profit maximization by competing platforms, results in equilibrium price-cost margins that are simple observable functions of the estimated demand parameters (and not of costs). With other types of demand specifications in which demands are interrelated, this property will generally not be true, and one requires full system estimation to obtain results. ${ }^{6}$

\section{Data}

Our initial data set comprises of quarterly information on cover prices, ad prices, number of ad pages ${ }^{7}$, number of content pages, and circulation numbers for German magazines that existed between the first quarter of 1972 and the fourth quarter of $2003 .^{8}$ The original source of our data is the Informationsgemeinschaft zur Feststellung der Verbreitung von Werbetraegern e. $V$. This association ascertains, monitors and publishes information on magazine dissemination and circulation.

We annualize our quarterly data given cover prices and ad rates do not change within a year. Our identification of markets with just two competing magazines ('two-magazine markets'), a prerequisite to the estimation of the theoretical model, proceeds in two steps. First, we place each magazine into a unique magazine segment (or magazine submarket) and then check in what periods between 1972 to 2003 the respective magazine group consisted of just two competing magazines. The initial magazine grouping follows industry convention. We use the grouping by Jahreszeitenverlag (1981-2003). ${ }^{9}$ Jahreszeitenverlag

\footnotetext{
${ }^{6}$ Other recent theoretical models of two-sided markets with competing platforms that apply to media markets, such as those by Anderson and Coate (2002), Ferrando et al. (2004) and Gabszewicz et al. (2001) all obtain a demand specification for advertising in which the demand for advertising only depends on the own per-viewer price of advertising, and not the ad rate or the number of readers of the rival platform. We test some alternative specifications of demand at the end of Section 5.

${ }^{7}$ For simplicity, we assume ads are all the same size, which we define as 'one page'. We do not have any systematic information about advertising sizes but sampling the magazines in our study revealed that most ads tended to be of the same size (which was one page).

${ }^{8}$ Our data and software code are available at http://www.ulrichkaiser.com/papers/twosided.html.

${ }^{9}$ Jahreszeitenverlag is a major German magazine publisher which made its annual publication Funktions-Analyse: Factbook für Inhalte und Portraits von Zeitschriften available to us upon request. We have access to the 'Factbooks' from 1992 to 2003.
} 
distinguishes between 35 different magazine groups. We search for two-magazine markets inside these 35 distinct groups and identify a total of 18 two-magazine markets that existed during our period of observation. The number of years of existence range between one and 31 years.

Table 1 gives an overview of our sample selection. All magazines are published in German, including those that are originally from foreign countries such as Elle and Vogue. Magazines also differ substantially from the original foreign version with respect to content (though not by layout). Since the foreign originals (or other similar foreign magazines) are difficult to obtain and are typically significantly more expensive, we do not believe that they impose a competitive constraint on the German equivalents.

Nine out of the 18 two-magazine markets are eliminated because of difficulties in their definitions or data. Due to missing data for some of the variables, we have to eliminate 'Fiction magazines'. With only observations on one year, we are also forced to eliminate 'Fitness', 'Youth' and 'Riddles' magazines, as we will be first-differencing our data. We do not consider 'Magazines with special character' (Neue Revue and Reader's Digest Das Beste) since they are completely different magazines. Neue Revue is concerned with the latest gossip surrounding European celebrities, while Reader's Digest Das Beste is the German version of Reader's Digest. We think a more appropriate label for these magazines would have been 'miscellaneous'. For similar reasons we also exclude 'Travel', 'Sports' and 'Young illustrated' magazines. ${ }^{10}$

In total, we are left with only 100 usable observations (91 after first differencing), so the usual caveats of empirical work with small samples apply. The nine two-magazine markets that we include in our estimation make up between 2.2 and 8.4 percent of the total number of titles published in the total German magazine market, between 0.4 and 5.3 percent of total circulation, and between 1.1 and 5.4 percent of total ad pages (in the time period 1972-2003).

The two most important groups (in terms of observations) are 'Do-It-yourself' magazines and 'Photography' magazines. Together, these account for 56 percent of all our usable observations. Some summary statistics on the variables involved in the estimation are given in Table 2. The mean cover price for a magazine in our sample is 2.85 Euros (across both magazines from all magazine groups), whereas advertisers pay on average 10,512 Euros per ad. A magazine in our sample has a circulation of about 955,577 per year on average (the median is 706,680), and runs about 673 ads per year. Magazines in our sample have slightly more than 3.1 content pages for every ad page. While some

\footnotetext{
${ }^{10}$ Specifically, the 'Travel' magazines come in a different periodicity and one magazine (Geo Saison) deals with a wide array of topics while the other one (Merian) exclusively is concerned with a single travel destination; kicker-sportmagazin, a 'Sports' magazine, exclusively reports about soccer events, while Sport Illustrierte covers a wide range of sport events; and Prinz, a 'Young illustrated' magazine, comes in 13 different regional editions, faces significant competition from local newspapers and free city magazines, and has its focus on reporting on local events, while Max is a regular lifestyle magazine aimed at people below 35 .
} 
magazines have almost no ads, no magazine in our sample has more ads than content. The minimum ratio of ad pages to all pages for any magazine-year in our sample is 0.057 while the maximum is 0.454 . A simple OLS regression of the ratio of ad pages to all pages on a constant, as well as linear and quadratic time trends, shows that the advertising ratio has changed over time, with the maximum ad share reached in 1989.

Our magazines are fairly symmetric, with the average deviation in readership market shares being 0.136 (a deviation which has been falling over time) and in advertising market shares being 0.098 (a ratio that has been rather steady). The correlation between the two market shares is 0.469 , and has been falling over time. A positive correlation is consistent with our model, which implies, ceteris paribus, higher demand on one side increases demand on the other side and vice-versa.

\section{Empirical specification}

Recall the empirical approach is to estimate the equations (1) and (3) so as to obtain estimates of the parameters $\gamma, \psi, \beta, \rho$, and $\eta$. We use GMM to jointly estimate the two equations using our panel data set. To remove magazine-group specific constants (magazine-group fixed effects) we first difference the data. Our estimated model is

$$
\begin{array}{ll}
\triangle & s_{1 t}=\gamma\left(\Delta N_{1 t}^{a}-\triangle N_{2 t}^{a}\right)+\psi\left(\Delta N_{1 t}^{c}-\triangle N_{2 t}^{c}\right)-\beta\left(\Delta p_{1 t}-\Delta p_{2 t}\right)+\Delta \varepsilon_{1 t}-\Delta \varepsilon_{2 t} \\
\triangle & n_{1 t}^{a}=\rho\left(\triangle S_{1 t}-\triangle S_{2 t}\right)-\eta\left(\triangle a_{1 t}-\Delta a_{2 t}\right)+\Delta \xi_{1 t}-\Delta \xi_{2 t},
\end{array}
$$

where $\Delta$ denotes the first difference operator.

All explanatory variables in (9) and (10) are potentially endogenous. We thus need to find suitable instruments for circulation, the number of content pages, the number of ad pages, cover prices, and ad rates.

Our main identifying assumption is that (unobserved) cost factors are common across magazines published by a magazine's publisher and that other (demand-side) shocks specific to the magazine are not correlated with these factors, an approach similar to that used by Hausman and Taylor (1981), Hausman et al. (1994) and Berry et al. (1995). This means that cover prices of a publisher's magazines in other segments of the magazine market are assumed to be driven by common underlying costs associated with a publisher's production, distribution and marketing of its magazines to readers. These costs also determine the particular magazine's cover prices, but are assumed to be uncorrelated with the disturbances in the magazine's product demand equations, which is why the average cover price of a publisher's other magazines can be used as instruments for cover prices. The same logic applies to the use of the average ad rate of a publisher's other magazines as an instrument for a magazine's ad rate, and the use of the average content pages per copy of a publisher's other magazines as an instrument for a magazine's content pages per copy. 
Additional cost-side instruments for cover prices, ad rates and content pages per copy are the natural logarithm of the number of magazine titles published by the own publisher in a given year (a proxy variable for returns to scope in production) and the the natural logarithm of the total number of pages printed by the own publisher in a given year (a proxy for returns to sale in production).

We also assume common (unobserved) demand factors affect publishers, and that these factors are uncorrelated with the magazine's marginal cost shocks. For instance, reflecting perhaps better management, some publishers at certain times may be better than others at attracting successful editors, across its whole range of magazines. Successful editors produce popular content that attracts a larger number of readers. Alternatively, a particular publisher may have access to a wider distribution channel than other publishers, resulting in higher demand for all its magazines. This suggests that a reasonable instrument for a magazine's circulation share is the average circulation share of the publisher's other magazines. Likewise, a similar logic applies to the advertising side. A particular publisher may form an ongoing relationship with a large advertising client through one of its magazines, but this will tend to raise demand for advertising in the publisher's other magazines, given some large advertisers may place ads across different magazine markets ("cross-selling" as it is termed in the media industry). Thus, we use the average advertising share of a publisher's other magazines to instrument for the advertising share of a particular magazine produced by the same publisher. Lagged endogenous variables are instrumented by the corresponding lagged instruments. Additional instruments are a constant, a linear and a quadratic time trend.

Our instruments show a high correlation with the explanatory variables. At the same time, the instruments can be formally tested for their statistical validity by using a test for orthogonality of the instruments with the residuals of the equations of interest. This test cannot reject orthogonality of the instruments at the usual significance level. ${ }^{11} \mathrm{~A}$ final undesirable property of share equations is that the error terms are heteroscedastic, which is corrected for by GMM estimation.

\section{Results}

GMM estimation results for the equations (9) and (10) are displayed in Table 3. Table 4 displays the corresponding non-instrumented seemingly unrelated regression (SUR) estimation results. GMM and SUR estimation results differ substantially. For instance, the SUR model produces a negative coefficient on the effect of the number of content pages on the demand by readers, which is economically implausible and underscores the importance of instrumentation.

\section{Magazine readership demand}

For GMM estimation, the relative number of content pages in one magazine versus its

\footnotetext{
${ }^{11}$ The details are available at http://www.ulrichkaiser.com/papers/twosided.html
} 
rival is found to be a significant determinant of the share of readers the magazine attracts within the magazine group. The parameter $\psi$ is positive and statistically significant (at the $5 \%$ level). Magazines with more content attract more readers. The elasticity of readership share to content share is $\psi N_{i}^{c} / s_{i}$. Over our sample, we find a 1 percent increase in the share of content that a magazine has (relative to total content pages of the twomagazine group) leads to an estimated 0.168 percent increase in the magazine (market) share of readers (the standard error is 0.083 implying the result is significant at the 5 percent level, given a $p$-value of 0.044 ). The relative number of ad pages is also found to be significant, both statistically and economically, for readership share. The equivalent elasticity of readership share on ad share is calculated as $\gamma N_{i}^{a} / s_{i}$, which over our sample implies an estimated elasticity of 0.335 (which is significant at all reasonable levels given a standard error of 0.048). Although it appears readership share is more sensitive to ad share than content share, we cannot reject equality of elasticities (Wald test statistic is $1.939, p$-value is 0.379 ).

Our parameter estimate for $\beta$, the coefficient on cover prices, is significantly different from zero suggesting that the difference in cover prices between two magazines is a significant determinant of readership share in our data. The estimated elasticity of readership share to cover price (measured as $-\beta p_{i} / s_{i}$ ) is -0.494 (the standard error is 0.168 implying the result is significant even at the 1 percent level, given a $p$-value of 0.003$)$. This suggests a 1 percent increase in price of magazine 1 leads to a 0.494 percent drop in the readership share of magazine 1 (over our sample).

We can use the estimates of $\psi, \gamma$ and $\beta$ to compare how much readers value content versus ads. For instance, an additional content page per year increases each reader's utility by $\psi$, so each reader's willingness to pay for this increase is $\psi / \beta$ Euros. Comparing this to $\gamma / \beta$, each reader's willingness to pay for one additional ad page per year, we find that after multiplying by the number of readers, readers in total are willing to pay 17,711 Euros for an extra 1 percent of content over a year (standard error is 6, 382, implying the result is significant given a $p$-value of 0.006 ), and they are willing to pay 34,064 Euros for an extra 1 percent of advertisements over a year (standard error is 14,366, implying the result is significant given a $p$-value of 0.018 ). Despite the fact it seems readers are willing to pay more for ads than for content, again we cannot reject equality of the two effects (Wald test statistic is $0.961, p$-value is 0.619 ).

\section{Magazine advertising demand}

The estimated advertising demand equation shows a significant effect of the circulation of one magazine versus its rival on the share of advertising the magazine attracts from within the magazine group. The parameter $\rho$ is positive and statistically significant at the 1 percent significance level. Magazines with more readers are able to attract more advertisers (for given ad rates). The estimated elasticity of advertising share to readership share (measured as $\rho S_{i} / n_{i}^{a}$ ) is 0.462 (which is significant at all reasonable levels given a standard error of 0.055 ). This suggests a 1 percent increase in the share of readers of magazine 1 increases the share of ads in magazine 1 (relative to the group) by 0.462 
percent (over our sample). We also find statistically significant and positive effects of the difference in ad rates between two magazines on their advertising shares. The estimated elasticity of advertising share to ad rates (measured as $-\eta a_{i} / n_{i}^{a}$ ) is -0.715 (which is significant at all reasonable levels given a standard error of 0.176 ). This suggests a 1 percent increase in the ad rate of magazine 1 leads to a 0.715 percent drop in the share of ads in magazine 1 (over our sample). These results imply advertisers (in total) are willing to pay 90,750 Euros to be able to reach an extra 1 percent of readers over a year (standard error is 26,459, implying the result is significant given a $p$-value of 0.001 ). Clearly, this is considerably more than the estimated 34,064 Euros readers are willing to pay in total to be able to read an extra 1 percent of ads over a year, although the difference between the two results is not statistically significant (Wald test statistic is $2.2073, p$-value is 0.332 ).

\section{Checking for non-explosive network effects}

For the equilibrium solutions of the theoretical model to be well defined, we require the expression $1-4 \rho \gamma N S$ to be positive. If not, network effects dominate, and the model predicts tipping to the case where one magazine takes the whole market. Using our parameter estimates, we calculate the estimated value of this expression over our sample is 0.547 , with a corresponding standard error of $0.055 .{ }^{12}$ Thus, we can easily reject explosive network effects. Demands implied by our estimated model are well behaved.

\section{Implied structure of prices-cost markups}

One of the key points of interest in a two-sided market is to understand the determinants of the structure of prices. How much is charged to readers versus advertisers? In the theoretical model we considered, one determinant of the structure of prices is the structure of costs. The price to readers will reflect the cost of making a sale to an additional reader (distribution and retailing costs), while the price charged to advertisers will reflect the cost of including an additional ad in the magazine (the costs of dealing with an additional client, and producing the ad). Since we do not measure or estimate costs, we concentrate instead on the structure of price-cost markups. Our particular Hotelling model, if valid, implies these price-cost markups can be recovered from the demand estimates alone.

Equations (6) and (7) specify the determinants of these price-cost markups. The first term in each case is a regular Hotelling type markup that reflects transportation cost or more generally, the degree of product differentiation. The model allows for magazines to be asymmetric, so this markup will also depend on the relative size of the magazine's customer pool. The estimate of the implied markup due to product differentiation for readers is 7.298 Euros per reader with a standard error of 2.487 ( $p$-value is 0.003 ). The equivalent estimate of the implied markup due to product differentiation for advertisers is 15,323 Euros per ad with a standard error of 3,775 ( $p$-value is 0.000 ). The apparently strong differentiation between magazines from advertisers' point of view raises the question of why firms view magazines as differentiated. The existing literature focuses on

\footnotetext{
${ }^{12}$ Standard errors are calculated using the 'Delta' method (e.g. Greene 2003, Section 5.4.2), which is also used below for other non-linear functions of parameters.
} 
the link between readership characteristics and ad rate across publishers, which provides one view of the source of differentiation (Thompson, 1989 and Koschat and Putsis, 2002). Another possibility is that other (non-readership) aspects also influence the choice of publisher/magazine. These include the location of the publisher relative to the advertising firm, the print quality of ads (glossy or ordinary), the lead time needed to meet the publication deadline, the possibility of a feature issue related to the firm's specific products, the possibility of cross-advertising possibilities with the publishers other magazines, and more generally, the level of service offered to the advertiser.

The additional terms in equations (6) and (7) are the network externality terms that arise from the two-sided nature of the market. In the case of the cover price markup, publishers will charge readers less when advertisers get more profits from advertising in magazines with more readers. By subsidizing readers, each magazine publisher attempts to attract more readers, and thereby more demand (profits) from advertisers. Similarly, by subsidizing advertisers, each publisher attempts to attract more ads so as to attract readers. Our estimates can provide some insight into which effect is more important.

The estimated network externality term $2 \rho N_{i}^{a} / \eta$ for the equilibrium cover price equation has a mean estimated value of 9.497 Euros per reader with a corresponding standard error of 2.769 ( $p$-value is 0.001). This is an estimate of how much magazines lower cover prices (in our sample) as a result of the fact advertisers value magazines with lots of readers. The result suggests magazines may actually set their cover prices below cost. In fact, the net effect of the product differentiation markup and the network externality discount is for magazines to set their cover price at 2.198 Euros below cost (note, however, the standard error on this estimate is 4.741 so the result is not significant at any reasonable level). In comparison, the mean cover price in our sample is 2.854 Euros. Using the equilibrium pricing relationship (6) to back out costs which generate the observed mean cover price implies average costs per reader of 5.052 Euros (the high standard error in the estimate of the price-cost margin means we could rationalise considerably lower costs also). According to these results, the magazines discount cover prices, so as to attract readers, and therefore more lucrative advertisers.

The estimated network externality term $2 \gamma S_{i} / \beta$ for the equilibrium advertising price equation has a mean estimated value of 5,059 Euros with a corresponding standard error of 2,133 Euros ( $p$-value is 0.018). This is an estimate of how much equilibrium ad rates will rise if magazine readers do not value ads. This represents an approximately 50 percent increase in the ad rate (the mean ad rate is 10,512 Euros). In percentage terms, this externality appears to be much smaller than that running in the opposite direction. The results imply that in a symmetric equilibrium, the magazines will set their ad rates at 10,264 Euros per ad above cost with a corresponding standard error of 5,518 Euros. Given actual average ad rates, the backed out costs implied by this result and (7) are costs of 247 Euros per ad, but with a standard error of 5,518 Euros in the price-cost margin, a wide range of observed costs can be consistent with these results.

\section{Sources of profit contributions}


As noted above, the results of our model lend support to the general perception that readers are subsidized and that magazines receive the bulk of their margins from advertisers. This is confirmed by calculating the direct contribution to profits from readers and from advertisers. We calculate the equilibrium price-cost markup for readers multiplied by the number of readers: $S_{i} / \beta-2 \rho N_{i}^{a} S_{i} / \eta$, which is a measure of the direct contribution to a magazine's equilibrium profits from readers. Based on our estimates, the implied value of this expression is $-2,145,360$ Euros (standard error 5,201,330) per year, so that on average, magazines in our sample make losses on the reader market. This is in accordance with other studies on print media markets, for example Ludwig (2003) and Wagner (1981). Given the insignificance of our estimate, an alternative way of stating this result is that we cannot reject the hypothesis that magazines obtain no direct profit contribution from the readership side.

Compare these results to the direct contribution to a magazine's profit from advertisers, which can be calculated as $N_{i}^{a} / \eta-2 \gamma N_{i}^{a} S_{i} / \beta$. The mean estimate over the sample is 7,035, 460 Euros (per year) with a standard error of 4,019,720 (the $p$-value is 0.080 ), so we can reject advertisers make no direct contribution to profits (although only at the 10 percent significance level). Based on these point estimates, magazines more than compensate for their losses on the reader market by gains on the advertising market. Of course, readers contribute to profits indirectly by raising demand from advertisers, but this is why readers are "subsidized" in the above equilibrium.

\section{Content pages production cost}

Unlike price-cost margins, we cannot determine the optimal level of content implied by the fitted model without knowing the content page production costs parameters $d_{i}$, since according to (8), $N_{i}^{c}=\psi S_{i} /\left(2 \beta d_{i}\right)$. However, in order to do comparative statics on the model, it is useful to back out the value of $d_{i}$ which makes the value of $N_{i}^{c}$ predicted by the model equal to its (average) counterpart in the data. Thus, we solve (8) for $d_{i}=\psi S_{i} /\left(2 N_{i}^{c} \beta\right)$, taking the mean over the sample. The implied level of $d_{i}$ is 0.124 . The implied value of the marginal production cost of a page of content from the model is then $m c_{i}=2 d_{i} N_{i}^{c}=\psi S_{i} / \beta$, which has a mean value (across all observations) of 442 Euros.

It is interesting to compare these cost estimates with direct measures of the magazines costs. We were able to obtain cost information on three German magazines - Der Spiegel, Zeit-Magazin and Stern in Ludwig (2003). Ludwig obtained his data, which refer to 1992, from case studies. Der Spiegel and Stern belong to the group of weekly political magazines, Zeit-Magazin is the supplement to Die Zeit, another weekly political magazine. None of the three magazines is part of our sample so comparing their cost data with our implied costs involves using our model "out-of-sample".

Ludwig (2003, p. 208) reports that the average per copy content page production cost is 0.96 Euros for Der Spiegel, 0.62 Euros for Zeit-Magazin and 0.75 Euros for Stern. The average per copy content production cost derived from our model is $d_{i}\left(N_{i}^{c}\right)^{2} / S_{i}$. Using the 1992 data for content pages $N_{i}^{c}$ we obtain the following implied costs for the three magazines: 0.42 Euro for Der Spiegel, 0.46 Euros for Zeit-Magazin, and 0.39 Euros for 
Stern. Our estimates are lower than Ludwig's, but not vastly different.

\section{Comparative statics in two-sided markets}

Another way to interpret our estimation results is to consider what happens if one magazine faces an exogenous change in its costs or demand parameters. In particular, we are interested in how a shock to a magazine on one side of the market affects its equilibrium price on the other side of the market. While under normal circumstances, an increase in magazine 1's costs or demand on the reader side will cause it to charge more to readers, it is not obvious how such shocks will affect its charges to advertisers. As we will show, in theory, an increase in cost or demand can increase or decrease the cross-market price, reflecting two opposing effects. We thus use our estimated parameters to determine which effect dominates.

Given the linear functional forms implied by the Hotelling model, the comparative static derivatives do not depend on the unknown parameters $f_{1}, f_{2}, c_{1}, c_{2}, b$ or $\phi$. Rather they only depend on the estimated parameters, and $\left.d_{(} i\right)$ which we set to 0.124 from above. We consider positive demand shocks on the reader side $(b)$ and on the advertising side $(\phi)$ for magazine 1 , as well as cost shocks on the reader side $\left(f_{1}\right)$ and on the advertising side $\left(c_{1}\right)$ for magazine 1 . The effect of the shocks is first obtained assuming network effects are absent (setting $\gamma=\rho=0$ ), and then allowing these to be equal to their estimated values. The results demonstrate an interesting asymmetry between how shocks to the advertising side affect the readership side and vice-versa.

Totally differentiating the system defined by (1)-(4) and (6)-(8) for $i=1$ and 2 , the impact of cost and demand shocks on prices on the opposite side are summarized in the following comparative static results

$$
\begin{aligned}
& \frac{d a_{1}}{d b}=-\frac{d a_{2}}{d b}=\frac{2\left(\rho-\frac{\gamma \eta}{\beta}\right) S}{\Delta} \\
& \frac{d p_{1}}{d \phi}=-\frac{d p_{2}}{d \phi}=\frac{2 \eta\left(\gamma-\frac{\beta \rho}{\eta}+\frac{\rho \psi^{2} S}{\eta d}\right) N}{\beta \Delta} \\
& \frac{d a_{1}}{d f_{1}}=-\frac{d a_{2}}{d f_{1}}=-\frac{2 \beta\left(\rho-\frac{\gamma \eta}{\beta}\right) S}{\Delta} \\
& \frac{d p_{1}}{d c_{1}}=-\frac{d p_{2}}{d c_{1}}=-\frac{2 \eta^{2}\left(\gamma-\frac{\beta}{\eta} \rho+\frac{\rho \psi^{2} S}{\eta d}\right) N}{\beta \Delta}
\end{aligned}
$$

where

$$
\Delta=9 \eta-\left(8 \beta \rho^{2} N S+20 \gamma \rho \eta N S+\frac{8 \gamma^{2} \eta^{2} N S}{\beta}+\frac{3 \psi^{2} \eta S}{\beta d}\right) .
$$

Consider first an exogenous increase in demand by readers for magazine 1 . We model this by considering an increase in $b$. When network effects are ignored, the results are standard. Magazine 1, facing higher demand, increases its cover price. As in a standard Hotelling model, when one firm enjoys an exogenous increase in demand at the expense of its rival, it will charge more (and its rival will charge less). Despite the price increase, 
magazine 1 still retains higher market share. In addition, the negative impact of the higher price on market share is partially offset by the fact that magazine 1 increases its production of content to take advantage of the higher equilibrium margins on readers. Our main interest is in what happens to the choice of advertising rates on the other side of the market. When network effects are assumed away, the answer is nothing.

Allowing for network effects, the theoretical implications for advertising rates of an increase in reader demand are ambiguous, and depend on the sign of the expression $\rho-\eta \gamma / \beta$. A high value of $\rho$ means that the exogenous increase in readership demand will translate into a relatively large increase in advertising demand. As a result, the magazine will want to increase its advertising rates to exploit this higher demand. With more readers, magazine 1 becomes superior from the advertisers' perspective, which allows magazine 1 to charge more to advertisers. We call this the cross-market demand effect. On the other hand, a high value of $\eta \gamma / \beta$ means that when magazine 1 enjoys higher margins on the reader side of the market (as a result of the exogenous increase in demand by readers), it will want to cut ad rates since doing so generates a large increase in advertisers (the $\eta$ effect), and the increase in advertisers generates a large increase in the now more profitable readers (the $\gamma$ effect). This effect has to be measured relative to the level of $\beta$, the sensitivity of reader demand to cover prices. If $\beta$ is high, then it does not make sense to cut ad prices a lot to generate the extra reader demand, when this demand can anyway be generated by a small decrease in cover prices. We call this effect the cross-market subsidy effect, since it captures the incentive for a magazine to subsidize one side to capture the higher margins on the other (now) more profitable side. Our estimated results imply the cross-market demand effect dominates the cross-market subsidy effect for a shock to reader demand. ${ }^{13}$

This result means the exogenous increase in demand from readers increases equilibrium charges to advertisers. Magazine 1 does not want to subsidise advertisers so as to attract a few more readers. Rather, it wants to exploit the larger effect of higher reader demand on advertising demand by charging advertisers more. We find $d a_{1} / d b=896.53$, so roughly speaking, an exogenous increase in magazine 1's market share of readers from 50 to 55 percent will cause it to charge advertisers 44.83 Euros more per ad.

Consider instead an exogenous increase in demand for advertising in magazine 1 . The increase in demand from advertisers leads magazine 1 to charge higher ad prices (the normal Hotelling response). Without network effects, there is no impact on the other side of the market (the equilibrium cover price and production of content remains unchanged). Allowing for network effects raises the question of how magazine 1 will adjust its cover price and production of content.

Whether magazine 1 will respond to the higher advertising demand and price by raising or lowering cover prices depends on the sign of the expression $\gamma-\left(1-\psi^{2} S / \beta d\right)(\beta \rho / \eta)$.

\footnotetext{
${ }^{13}$ Using the delta approach to obtain the standard error on $\rho-\eta \gamma / \beta$, we find we can reject at the $5 \%$ level that this expression is zero in favor of the alternative, which is that it is positive ( $p$-value is 0.0152 from this one-sided test).
} 
If the cross-market demand effect $(\gamma)$ dominates, then higher advertising demand will increase reader demand sufficiently such that magazine 1 will want to increase its cover price. If, on the other hand, the cross-market subsidy effect $(\beta \rho / \eta)$ dominates, then higher advertising demand will cause magazine 1 to lower its cover price. Lower cover prices enable magazine 1 to attract more readers, and thereby more advertisers, so as to profit from its now higher margin on advertisers. The cross-market subsidy effect is weakened somewhat by the ability of magazine 1 to attract more readers by producing more content rather than lowering the cover price. This is measured by the term $\left(1-\psi^{2} S / \beta d\right)$, which reduces the cross-market subsidy effect by about 23 percent in our sample. Despite this, we still find the cross-market subsidy effect dominates in this direction, so that the magazine will actually decrease its cover price in response to the demand increase from advertisers (and it will also increase its production of content). ${ }^{14}$

Our estimates imply $d p_{1} / d \phi=-1.768$, which suggests an increase in advertising market share from 50 to 55 percent will cause magazine 1 to charge readers 9 Euro cents less, and to produce an additional 21 content pages. These results provide another sense in which advertisers care more about the number of readers than vice-versa. A positive shock to reader demand raises a magazine's equilibrium ad rate, whereas a positive shock to advertising demand lowers a magazine's cover price. These differing responses reflect that, when measured relative to how easy it is to attract each type of user by adjusting prices, it is easier to attract more advertisers by subsidizing readers than vice-versa.

We repeat the above exercises but with cost shocks rather than demand shocks. Without network effects, the effect of an increase in costs on a magazine's demand and margins is the opposite to that of an increase in demand. Facing higher cost on one side of the market, magazine 1 raises its respective price, but not one-for-one given its rival's cost has not changed. The result is a reduction in the magazine's demand and margins on the particular side of the market. Allowing for network effects thus causes cost shocks to have the opposite effect on the cross-market prices as demand shocks. Specifically, if the costs of each reader increases for magazine 1 , then magazine 1 will respond to the decreased equilibrium number of readers by lowering its price to advertisers. For instance, an increase in the cost to magazine 1 of one Euro per reader leads the magazine to decrease its ad rate by 61.42 Euros. In contrast, if the cost of providing each ad increases for magazine 1, then magazine 1 will respond to the lower advertising margins by increasing the cover price to readers, since "subsidizing" readers to attract advertisers is no longer so profitable. For example, a 1,000 Euro increase in the cost to magazine 1 of providing an ad, leads the magazine to increase its cover price by around six Euro cents, and cut the number of its content pages by about 14 pages.

\section{Separate magazine group estimates}

Magazine group fixed effects drop out from our estimation equations since we esti-

\footnotetext{
${ }^{14}$ Note that the sign of $\gamma-\beta \rho / \eta$ is the opposite of $\rho-\gamma \eta / \beta$, so provided the term $\left(1-\psi^{2} S / \beta d\right)$ is sufficiently small, this result follows from our previous result.
} 
mate our model in first differences. It may, of course, be the case that the slope coefficients are different for each magazine group and that the estimates for each magazine group deviate significantly from our results obtained from the pooled estimation. With on average about ten observations per magazine group, it is not feasible to allow slope coefficients to vary across each group. However, one can provide some evidence on whether each of the parameter values varies between one of the larger magazine groups and the rest of the groups. We conduct such a test with our two largest magazine groups, 'Photo magazines' (29 observations after first taking differences) and 'Do-It-Yourself magazines' (23 observations after taking first differences). Specifically, we test for whether each coefficient varies between one of these groups separately and the estimate when all magazines are included. For instance, to see whether $\gamma$ varies between 'Photo magazines' and that for our pooled data, we estimate $\gamma_{g} / \gamma$ from $\Delta s_{1 t}=$ $\gamma\left(\Delta N_{1 t}^{a}-\Delta N_{2 t}^{a}\right)+\psi\left(\Delta N_{1 t}^{c}-\Delta N_{2 t}^{c}\right)-\beta\left(\Delta p_{1 t}-\Delta p_{2 t}\right)+D_{g} \gamma_{g}\left(\Delta N_{1 t}^{a}-\Delta N_{2 t}^{a}\right)$, where $D_{g}$ denotes a group dummy (here, it takes the value one for the photo group). The coefficient $\gamma_{g}$ is then the deviation of the estimate of $\gamma$ from 'Photo magazines' from the coefficient estimate when all magazines are pooled, and $\gamma_{g} / \gamma$ scales this deviation by the level of the estimate to allow comparison across parameters. Table 5 provides the results. The majority of the coefficient estimates remain stable across the separate groups. Statistically, the parameter estimates seem to be less stable on the advertising side, although in terms of the magnitude of the effects, the largest deviations arise from the parameter $\gamma$ (the extent to with readers value ads), even though this deviation is not statistically significant.

\section{Alternative demand models}

The demand system we estimate in (9) and (10) is linear when specified in market shares. An alternative specification is that a magazine's share of advertisers just depends on the respective ad rates per subscriber. Thus, we consider the alternative model

$$
\begin{array}{ll}
\triangle & s_{1 t}=\gamma\left(\triangle N_{1 t}^{a}-\triangle N_{2 t}^{a}\right)+\psi\left(\triangle N_{1 t}^{c}-\triangle N_{2 t}^{c}\right)-\beta\left(\triangle p_{1 t}-\triangle p_{2 t}\right)+\text { error }_{1} \\
\triangle & n_{1 t}^{a}=\kappa\left(\triangle\left(a_{2 t} / S_{2 t}\right)-\triangle\left(a_{1 t} / S_{1 t}\right)\right)+\text { error }_{2}
\end{array}
$$

The readership share equation is specified as before, but now the advertising share equation depends on the ratio of ad rates to the number of readers. Given this new model and our model are not nested, we apply the "encompassing" test (Mizon, 1984). The empirical strategy is to re-run the demand system estimation, this time inserting the explanatory variables from both our demand model and the alternative model. We then run a "non-nested" F-test for significance of the model parameters of our model and the alternative model. Performing such a test for our model against model (17) leads to an $F$ statistics for the parameter of our model, $\rho$ and $\eta$, of 50.622 (p-value 0.000 ). The $F$ statistic corresponding to the parameter of the alternative model, $\kappa$, is 0.172 (p-value 0.679), so that we cannot accept the alternative model.

A different form suggested by some theoretical papers that have advertisers signing up to both publishers (multihoming) is that advertising is purely a function of the ad rate to subscriber ratio at each magazine, and there is effectively no competition across 
publishers on this side of the market. ${ }^{15}$ A modification of our specification which captures this possibility is the following

$$
\begin{array}{ll}
\triangle & s_{1 t}=\gamma\left(\triangle N_{1 t}^{a}-\triangle N_{2 t}^{a}\right)+\psi\left(\triangle N_{1 t}^{c}-\triangle N_{2 t}^{c}\right)-\beta\left(\triangle p_{1 t}-\triangle p_{2 t}\right)+\triangle \varepsilon_{1 t}-\triangle \varepsilon_{2 t}(18 \\
\triangle & N_{1 t}^{a}=\kappa_{1}\left(\triangle\left(a_{1 t} / S_{1 t}\right)\right)+\text { error }_{1} \\
\triangle & N_{2 t}^{a}=\kappa_{2}\left(\triangle\left(a_{2 t} / S_{2 t}\right)+\text { error }_{2}\right.
\end{array}
$$

Although this leads to similar estimates of (18) to our benchmark model, the estimates of $\kappa_{1}$ and $\kappa_{2}$ are insignificant at all reasonable levels of significance (furthermore $\kappa_{1}$ is negative and $\kappa_{2}$ is positive). An "encompassing" test leads to the result that we cannot reject either model. However, the $F$ statistic for the probability of not accepting our model is 264.628 ( $p$-value is 0.000$){ }^{16}$ while the $F$ statistic for the probability of not accepting this alternative model is 4.757 ( $p$-value is 0.011), suggesting we are more likely to reject the alternative model. The fact that the alternative model produces implausible parameter estimates of $\kappa_{1}$ and $\kappa_{2}$ suggests some misspecification in the model of (19) and (20).

\section{Conclusions}

In this paper, we obtained estimates of the parameters of a two-sided market model of competing magazine publishers. Using panel data from the German magazine industry between 1972 and 2003, we find non-explosive network benefits, so that the estimated demand system is well behaved. We ask, what is the markup charged to advertisers relative to that charged to readers? Our results are consistent with the conventional wisdom that advertisers value readers more than readers value advertisements, and that as a result, magazines "subsidize" cover prices, and make their profit from advertisers.

We apply this estimated model to consider cross-market comparative statics. Reflecting that advertisers value readers more than readers value advertisers, we find an increase in reader demand results in an increase in ad rates while an increase in advertising demand results in a decrease in cover prices. This asymmetric result reflects the incentive to subsidize readers to attract additional advertisers when the advertising side becomes more lucrative, but not vice-versa. Rather, if demand on the reader side increases (or costs fall), our estimated model implies there is an incentive to increase ad rates so as exploit the resulting increased demand on the advertising side.

Given the limited data used in this study, we treat our results as illustrative. The approach used shows how one can draw conclusions on the role of network effects in

\footnotetext{
${ }^{15}$ See footnote 7 for a brief discussion of this literature.

${ }^{16}$ To perform a test for encompassing, the dependent variable needs to be identical, which is why we multiply both sides of our advertising demand model by $N$ to transform it into a level equation as in the alternative model. We also estimate both demand equations implied by our model.
} 
determining the structure of pricing in studying two-sided markets. Future work could explore collecting and using a more extensive data set on magazine pricing. One approach worth considering is to use international data on specific magazines segments, where magazine segments in different countries, regions or languages can be considered to have different demands and costs, and for which the demand from each side of the market (advertising versus readership) should depend on country/region specific factors that can be observed.

\section{References}

Armstrong, M. (2004) "Competition in two-sided markets," mimeo, University College London.

Berry, S., J. Levinsohn, and A. Pakes (1995) "Automobile Prices in Market Equilibrium," Econometrica, 63, 841-890.

Bucklin, R.E., R. Caves and A.W. Lo (1989) "Games of survival in the US newspaper industry," Applied Economics 21, 631-649.

Caillaud, B. and B. Jullien (2003) "Chicken \& Egg: Competition Among Intermediation Service Providers," RAND Journal of Economics 34, 309-328.

Dertouzos, J.N. and W.B. Trautman (1990) "Economic effects of media concentration: estimates from a model of the newspaper firm," Journal of Industrial Economics $39(1), 1-14$.

Dewenter, R. (2003) "The Economics of Media Markets," University of the Federal Armed Forces Hamburg. Discussion Paper No. 10.

Doganoglu, T. and J. Wright (2004) "Multihoming and compatibility," mimeo, National University of Singapore.

Evans, D. (2003a) "The Antitrust Economics of Multi-Sided Platform Markets," Yale Journal on Regulation, forthcoming.

Evans, D. (2003b) "Some Empirical Aspects of Multi-sided Platform Industries," Review of Network Economics 2, 1-20.

Ferrando, J., J.J. Gabszewics, D. Laussel and N. Sonnac (2003) "Two-sided network effects and competition: an application to media industries," Université de Louvain working paper.

Gabszewicz, J.J., D. Laussel and N. Sonnac (2001) "Press advertising and the ascent of the 'Pensée unique'," European Economic Review 45, 645-651.

Gandall, N., M. Kende and R. Rob (2000) "The dynamics of technological adoption in hardware/software systems: The case of compact disk players," Rand Journal of Economics 31(1), 43-61. 
Greene, W. (2003) "Econometric Analysis (4th international edition)," Prentice-Hall, Upper Saddle River.

Hausman, J. and W. Taylor (1981) "Panel and Unobservable Individual Effects," Econometrica 49, 1377-1398.

Hausman, J., G. Leonard, and J. D. Zona (1994) "Competitive Analysis with Differentiated Products," Annales D'Economie et de Statistique, 34, 159-80.

Jahreszeitenverlag (1981-2003). "Funktions-Analyse: Factbook für Inhalte und Portaits vvon Zeitschriften," Jahreszeitenverlag, Hamburg.

Kaiser, U. (2003) "The effects of website provision on the demand for German women's magazines," University of Southern Denmark mimeo.

Koschat, M. and W. Putsis. (2002) "Audience characteristics and bundling: a hedonic analysis of magazine advertising rates," Journal of Marketing Research 39(3), 262273.

Ludwig, J. (1996) "Wie sich publizistische Hochkultur 'rechnet': Ein ökonomisches Porträt der 'Zeit'," Publizistik 41(3), 277-297.

Ludwig, J. (2003) "Mikroökonomie der Medien," in Altmeppen, K.-D. and M. Karmasin (Eds.) Grundlagen der Medienökonomie: Kommunikations- und Medienwissenschaft, Westdeutscher Verlag, Opladen, 187-214.

Mizon, G.E. (1984) "The Encompassing Approach in Econometrics," in Wallis, K.F. and D.F. Hendry (Eds.) Quantitative Economics and Econometric Analysis, Basil Blackwell, Oxford, 135-172.

Reddaway, W.B. (1963) "The economics of newspapers," The Economic Journal 73, 201-218.

Rochet, J-C. and J. Tirole (2003) "Platform Competition in Two-Sided Markets," Journal of the European Economics Association 1, 990-1029.

Rochet, J-C. and J. Tirole (2004) "Defining Two-Sided Markets," mimeo, IDEI and GREMAQ, Toulouse.

Rosse, J.N. (1967) "Daily newspapers, monopolistic competition, and economies of scale," American Economic Review 57(2), 522-533.

Rosse, J.N. (1970) "Estimating cost function parameters without using cost data: illustrated methodology," Econometrica 38(2), 256-275.

Rysman, M. (2004), "Competition Between Networks: A Study of the Market for Yellow Pages," Review of Economic Studies 71(2), 483-512.

Saloner, G. and A. Shepard (1995) "Adoption of Technologies with network effects: An empirical examination of the adoption of Automated Teller Machines," Rand Journal of Economics 26, 479-501. 
Thompson, R.S. (1984) "Structure and conduct in local advertising markets: the case of Irish newspapers," Journal of Industrial Economics 33(2), 241-249.

Thompson, R.S. (1989) "Circulation versus advertiser appeal in the newspaper industry: an empirical investigation," Journal of Industrial Economics 37(3), 259-271.

Wagner, K. (1981) "The newspaper industry in Britain, Germany and the United States," National Institute Economic Review 95, 81-88.

\section{A Appendix: Demand systems}

In this appendix, we detail the theoretical model which leads to the demand system estimated. Suppose there is a measure $S$ of consumers who will buy from one of the two rival magazines. These consumers are located at $x$, where $x$ is uniformly distributed on the unit interval $[0,1]$, and the magazines are located at either ends of the interval. Suppose a consumer located at $x$ gets net utility $v_{1}$ if she subscribes to magazine 1 , where

$$
U_{1}=v_{0}+b+\gamma N_{1}^{a}+\psi N_{1}^{c}-\beta p_{1}+\varepsilon_{1}-\frac{x}{2}
$$

and gets net utility $v_{2}$ if she subscribes to magazine 2 , where

$$
U_{2}=v_{0}+\gamma N_{2}^{a}+\psi N_{2}^{c}-\beta p_{2}+\varepsilon_{2}-\frac{1-x}{2} .
$$

We have normalized the Hotelling transportation cost to one half, and allowed for different degrees of product differentiation by introducing the parameter $\beta$ on prices.

The utility of reading a magazine is assumed to be a linear function of the number of pages of 'ads' $N_{i}^{a}$ in magazine $i$, and the number of pages of content $N_{i}^{c}$ in magazine $i$. The consumers' net utility is decreasing in the price charged by magazine $i$, denoted $p_{i}$. These three variables are observable. The remaining variables are unobservable. The parameter $v_{0}$ is assumed to be high enough so that all consumers want to buy one of the magazines. The parameter $b$ measures the intrinsic consumer preference for magazine 1 over magazine 2 ; that is, brand loyalty. The random variable $\varepsilon_{i}$ has mean zero and measures the unobservable intrinsic benefits of subscribing to magazine $i$ that all consumers obtain (these will be allowed to vary over time in the empirical model).

Given this specification of readers' utility, the number of readers obtained by magazine 1 is

$$
S_{1}=\left(\frac{1}{2}+b+\left(\gamma N_{1}^{a}+\psi N_{1}^{c}-\beta p_{1}\right)-\left(\gamma N_{2}^{a}+\psi N_{2}^{c}-\beta p_{2}\right)+\varepsilon_{1}-\varepsilon_{2}\right) S
$$

and

$$
S_{2}=S-S_{1}
$$

Dividing (21) and (22) by $S$ gives expressions for market shares. Despite the error terms $\varepsilon_{i}$, we assume these theoretical market shares lie between 0 and 1 , which they will do by construction in the data.

The advertisers' choice of magazine is modelled in a similar way. There is a measure $N$ of firms that will advertise in one of the two magazines. Let $a_{i}$ be the ad price set 
by magazine $i$. Then a firm gets a contribution to profit from advertising in magazine $i$ that is assumed to be a linear function of the number of readers of the magazine, and the price they are charged for the ad $a_{i}$, as well as some exogenous preference for each of the magazines. This preference for a particular publisher can capture how well the magazine's target audience fits with the firm's ideal target audience (assuming, for instance, a reader's choice of magazine correlates with some other variables such as income or location, which the advertiser cares about). Alternatively, the advertiser's choice of publisher might relate to other (non-readership) aspects, such as the location of the publisher relative to the advertising firm, the print quality of ads (glossy or ordinary paper), the lead time needed to meet the publication deadline, the possibility of a feature issue related to the firm's specific products, any cross-advertising possibilities in the publishers other magazines, and more generally, the service level offered to the advertiser. To model these varied factors that differentiate publishers, we simply suppose firms are located uniformly on the unit interval $[0,1]$, with transportation costs for a firm located at $y$ of $y / 2$ for advertising in magazine 1 and transportation costs $(1-y) / 2$ for advertising in magazine 2 (and allow for varying degrees of product differentiation by introducing a parameter on ad rates).

The contribution to a firm's profits of advertising in magazine 1 is thus given as

$$
\pi_{1}=\pi_{0}+\phi+\rho S_{1}-\eta a_{1}+\xi_{1}-\frac{y}{2}
$$

and the contribution to a firm's profit of advertising in magazine 2 is

$$
\pi_{2}=\pi_{0}+\rho S_{2}-\eta a_{2}+\xi_{2}-\frac{1-y}{2}
$$

where $\xi_{i}$ is some mean zero unobservable "benefit" firms get from having an ad in magazine $i$, which will be allowed to vary through time. The parameter $\phi$ measures the intrinsic preference of advertisers for magazine 1 over magazine 2 (the brand loyalty of magazine 1), while $\pi_{0}$ is assumed to be high enough so that all firms want to advertise in one of the magazines. Since there is assumed to be one ad per firm, the number of ads in each magazine will be equal to

$$
N_{1}^{a}=\left(\frac{1}{2}+\phi+\left(\rho S_{1}-\eta a_{1}\right)-\left(\rho S_{2}-\eta a_{2}\right)+\xi_{1}-\xi_{2}\right) N
$$

and

$$
N_{2}^{a}=N-N_{1}^{a}
$$

Dividing (23) and (24) by $N$ gives expressions for market shares. Again, despite the random error term $\xi_{i}$, we assume these theoretical market shares lie between 0 and 1 , which they will do by construction in the data.

\section{B Appendix: Multihoming}

In this appendix we show how our model can be extended in a way that ensures our existing results still apply even when some people read two (rival) magazines and some firms put the same ad in two (rival) magazines. Following the literature on two-sided 
markets, we call this situation "multihoming". This appendix also provides evidence that multihoming is not widespread on either side of the magazine markets we consider. Both findings suggest our results should be robust to the presence of multihoming users.

The extension of our model follows Doganoglu and Wright (2004). They allow for partial multihoming in a generic model by allowing for two types of agents on each side - those with a high network benefit parameter who always choose to multihome and those with a low network benefit parameter who always choose a single platform (singlehome). In the context of our model, we define the proportion of high-types on the reader side as $\lambda_{R}$ and the proportion of high-types on the advertiser side as $\lambda_{A}$. Consistent with Doganoglu and Wright, we assume these parameters are fixed. If there are $R_{1}$ readers who buy magazine 1 exclusively, $R_{2}$ readers who buy magazine exclusively, and $R_{M}$ who buy both magazines, then $\lambda_{R}=R_{M} /\left(R_{1}+R_{2}+R_{M}\right)$. Likewise, $\lambda_{A}=A_{M} /\left(A_{1}+A_{2}+A_{M}\right)$ where $A$ denotes the number of advertisers. Using our earlier notation, the total number of readers of magazine $i$ can then be written as $S_{i}=R_{i}+R_{M}$, and likewise for advertisers, $N_{i}^{a}=A_{i}+A_{M}$. Then $S=S_{1}+S_{2}=R_{1}+R_{2}+2 R_{M}$ and $N=N_{1}^{a}+N_{2}^{a}=A_{1}+A_{2}+2 A_{M}$.

Denoting the market shares of magazine 1 for low type readers and advertisers as $s_{1}^{L}$ and $n_{1}^{L}$ respectively, the previous market share equations (1)-(4) still apply as before to these types of agents. The inclusion (or not) of multihoming agents is irrelevant to the low types' decision of which magazine to choose, since users get the benefit of these multihoming agents regardless of which magazine they choose. However, the left hand side share terms in these equations now only apply for low types (which we do not observe directly), so these have to be rewritten in terms of observables. For instance, on the readership side we use the observed value of $s_{1}=S_{1} /\left(S_{1}+S_{2}\right)$ in the estimation of (1), but the market share implied by the theory is now $s_{1}^{L}=R_{1} /\left(R_{1}+R_{2}\right)$. Using the definitions of $\lambda_{R}$ and $S_{i}$ above, we can rewrite $s_{1}^{L}$ in terms of observables (and likewise for $\left.n_{1}^{L}\right)$ so that $s_{i}^{L}=\left(\left(1+\lambda_{R}\right) s_{i}-\lambda_{R}\right) /\left(1-\lambda_{R}\right)$ and $n_{i}^{L}=\left(\left(1+\lambda_{A}\right) n_{i}^{a}-\lambda_{A}\right) /\left(1-\lambda_{A}\right)$, which when substituted into the share equations (1)-(4) yield

$$
\begin{aligned}
s_{1} & =\frac{1}{2}+\left(\frac{1-\lambda_{R}}{1+\lambda_{R}}\right)\left(b+\gamma\left(N_{1}^{a}-N_{2}^{a}\right)+\psi\left(N_{1}^{c}-N_{2}^{c}\right)-\beta\left(p_{1}-p_{2}\right)+\varepsilon_{1}-\varepsilon_{2}\right) \\
s_{2} & =1-s_{1} \\
n_{1}^{a} & =\frac{1}{2}+\left(\frac{1-\lambda_{A}}{1+\lambda_{A}}\right)\left(\phi+\rho\left(S_{1}-S_{2}\right)-\eta\left(a_{1}-a_{2}\right)+\xi_{1}-\xi_{2}\right) \\
n_{2}^{a} & =1-n_{1}^{a}
\end{aligned}
$$

After taking first differences, the implied demand system becomes statistically identical to that in (9) and (10). Assuming that magazines cannot set different prices depending on whether agents singlehome or multihome, the profit function for each magazine is identical to that in (5), where $S_{i}=s_{i} S$ and $s_{i}$ is now defined in (25), and where $N_{i}^{a}=n_{i}^{a} N$ and $n_{i}^{a}$ is now defined in (27). Since the estimated demand system is the same as before, all our implied results using the first order conditions (6)-(8) still apply. The only difference arises from the interpretation of the underlying parameters, which if calculated by using the adjustment terms above, apply to the utility functions for low type agents on each side of the market. (By construction, high types will have higher values of $\gamma$ and $\rho$ than low types, but the same values of $\psi, \beta$, and $\eta$.) 
To give some idea of how many agents multihome, we calculate values for $\lambda_{R}$ and $\lambda_{A}$, the proportion of readers who multihome and the proportion of advertisers who multihome. Unfortunately, we do not have systematic information on multihoming for all magazines or all years in our sample. Instead, we collected information on multihoming from two sources. On the reader side, we have consumer survey data for most of the magazines in our sample from 1997-2003. On the advertisers side, we purchased all available magazines in our sample published in September 2004 and counted duplicated ads.

Information on multiple readership of magazines from the same magazine group is taken from AG.MA, as described in Section 3. The original source of the AG.MA data is a consumer survey that is biannually collected by the "Institut für Demoskopie, Allensbach". Around 20,000 interviews are conducted annually in Germany. This data contains information on what fraction of magazine 1's readers also read the next available issue of magazine 2 (and vice-versa). ${ }^{17}$ If we define the fraction of readers of magazine $i$ who also read magazine $j$ as $\lambda_{i, j}$, so $\lambda_{i, j}=R_{M} /\left(R_{i}+R_{M}\right)$, then $\lambda_{R}$ can be calculated from the observed $\lambda_{i, j}$ ratios by taking the inverse of $1 / \lambda_{i, j}+1 / \lambda_{j, i}-1$. The results, reported in table 6 , indicate multihoming on the reader-side is typically in the $5-10$ percent range. Taking the weighted average value from table 6 , using the number of observations on each magazine group as the weights, implies $\lambda_{R}=0.0786$.

To obtain a measure of the degree of multihoming amongst advertisers, we analyzed magazines in our sample for issues published in September 2004 by purchasing all available magazines in our sample on September 8th, 2004. Magazines from the same magazine group were published either the same day (in the case of weekly magazines) or the same month (in the case of monthly magazines). Only Goldene Gesundheit was unavailable as it exited the market in June 1997.

Counting ads within each two-magazine group that appear in both magazines simultaneously, and dividing by the total number of distinct ads within the group, we obtain multihoming percentages of 10.29 percent for 'Entertaining', 14.29 percent for 'Photo', 16.66 percent for 'Do-it-yourself', 17.95 percent for 'Food', 15.00 percent for 'Gardening', 10.63 percent for 'Monthly high priced women's', 37.21 percent for 'Weekly counselling women's', and 30.16 percent for 'PC'. These numbers indicate a higher degree of multihoming on the advertising side than the reader side. Taking the weighted average value, using the number of observations on each magazine group as the weights, implies $\lambda_{A}=0.169$.

The presence of multihoming agents implies our estimated parameters understate the true magnitude of parameters in the agents' utility functions. The above results give an idea of how much parameter estimates need to be scaled up on each side. Specifically, the estimated parameters $\widehat{\gamma}, \widehat{\psi}$ and $\widehat{\beta}$ in table 3 should be multiplied by 1.171 to get the parameter values which apply to the singlehoming readers. Likewise, the estimated parameters $\widehat{\rho}$ and $\widehat{\eta}$ in table 3 should be multiplied by 1.407 to get the parameter values

\footnotetext{
${ }^{17}$ This measure may overstate the level of multihoming for two reasons. First, people may be more likely to read, say, Madame one month and Vogue the next, than to read both magazines in the same month. It also seems likely that the degree of multihoming will be higher in readership than in actual purchase.
} 
which apply to the singlehoming advertisers. However, to the extent the model above is valid, none of our implied results are affected by this scaling since they are based on the estimated demand system, which remains valid under the assumptions of the model. To the extent the assumptions of the extended model are not valid, the relatively low proportion of multihoming agents for the markets we study suggests that our results should not be affected too greatly. 
Table 1: Sample selection

$\begin{array}{ll}\begin{array}{l}\text { Segment } \\ \text { Included magazines }\end{array} & \text { Title 1 } \\ \text { Health } & \text { Goldene Ges. } \\ \text { Entertaining } & \text { Bunte } \\ \text { Photo } & \text { Color Foto } \\ \text { Food } & \text { SelberMachen } \\ \text { Gardening } & \text { Essen \& Trinken } \\ \text { M. high priced women's } & \text { Mara } \\ \text { W. counselling women's } & \text { Bella } \\ \text { PC } & \text { Chip } \\ \text { Excluded magazines } & \text { Neue Revue } \\ \text { Mag. w/ spec. char. } & \text { Geo Saison } \\ \text { Travel } & \text { Max } \\ \text { Young illustrated } & \text { Tempo } \\ \text { City/lifestyle } & \text { Sport Illustrierte } \\ \text { Sports } & \text { Fit for Fun } \\ \text { Fitness } & \text { Bravo } \\ \text { Youth } & \text { Extra Rätsel } \\ \text { Riddles } & \text { Romanwoche } \\ \text { Fiction } & \end{array}$

Title 2

Medizin heute

Gala

fotoMAGAZIN

Selbst ist der Mann

Meine Familie \& Ich

Mein schöner Garten

Vogue

Tina

PC Welt

Readers Digest Das Beste

Merian

Prinz

Wiener

kicker-sportmagazin

Vital

Musikexpress

Freizeit Revue

Meine Geschichte
Period

Begin

$1979 \mathrm{Q} 2$

$1994 \mathrm{Q} 21999 \mathrm{Q} 1$

1972 Q3 2003 Q4

1979 Q1 2003 Q4

1973 Q2 1986 Q3

1986 Q2 1998 Q1

1983 Q1 1988 Q3

1979 Q3 1983 Q1

1985.Q2 1993.Q2

1972 Q3 1990 Q4

1990 Q1 2003 Q4

$1991 \mathrm{Q} 12003 \mathrm{Q} 4$

1986 Q4 1994 Q3

1972 Q3 1976 Q3

$1994 \mathrm{Q} 21995 \mathrm{Q} 4$

1977 Q1 1977 Q4

1985 Q1 1986 Q1

1984 Q1 2003 Q4
Obs

2
4
31
25
12
11
5
3
7
18
14
13
7
3
1
1
1
0

Table 2: Summary statistics for magazine titles

\begin{tabular}{lrrr}
\hline \hline & Median & Mean & Std. Dev. \\
\hline Circulation $\left(S_{i}\right)$ & 706,681 & 955,577 & $1,081,557$ \\
Advertisements $\left(N_{i}^{a}\right)$ & 471.8 & 673.3 & 527.7 \\
Content pages $\left(N_{i}^{c}\right)$ & 1,582 & 2,003 & 1,170 \\
Cover prices $\left(p_{i}\right)$ & 2.668 & 2.854 & 1.170 \\
Ad rates $\left(a_{i}\right)$ & 10,021 & 10,512 & 4,128 \\
\hline \hline
\end{tabular}


Table 3: GMM estimation results from the share equations

\begin{tabular}{lrrr}
\hline \hline & Coeff. & Std. Err. & $p$-value \\
\hline Readers value ads $(\gamma)$ & 0.1813 & 0.0259 & 0.000 \\
Readers value content $(\psi)$ & 0.0317 & 0.0157 & 0.044 \\
Competition for readers $(\beta)$ & 0.0685 & 0.0233 & 0.003 \\
Advertisers value readers $(\rho)$ & 0.2301 & 0.0276 & 0.000 \\
Competition for advertisers $(\eta)$ & 0.0326 & 0.0080 & 0.000 \\
\hline \hline
\end{tabular}

Note: For readibility, estimated coefficients and standard errors are all multiplied by one thousand except for $\rho$ where they are multiplied by one million, and for $\beta$ where they are left unchanged.

Table 4: SUR estimation results of share equations

\begin{tabular}{lrrr}
\hline \hline & Coeff. & Std. Err. & $p$-value \\
\hline Readers value ads $(\gamma)$ & 0.2537 & 0.0336 & 0.000 \\
Readers value content $(\psi)$ & -0.0200 & 0.0145 & 0.166 \\
Competition for readers $(\beta)$ & 0.0272 & 0.0209 & 0.194 \\
Advertisers value readers $(\rho)$ & 0.2296 & 0.0451 & 0.000 \\
Competition for advertisers $(\eta)$ & 0.0159 & 0.0117 & 0.172 \\
\hline \hline
\end{tabular}

Note: For readibility, estimated coefficients and standard errors are all multiplied by one thousand except for $\rho$ where they are multiplied by one million, and for $\beta$ where they are left unchanged.

Table 5: Allowing coefficients to differ across groups

\begin{tabular}{lrrrr}
\hline \hline & \multicolumn{2}{c}{ Do-it-yourself } & \multicolumn{2}{c}{ Photo } \\
& as separate group & \multicolumn{2}{c}{ as separate group } \\
& Coeff. & $p$-value & Coeff. & $p$-value \\
\hline Readers value ads $\left(\gamma_{g} / \gamma\right)$ & -3.1538 & 0.4578 & -6.9623 & 0.3561 \\
Readers value content $\left(\psi_{g} / \psi\right)$ & -3.2381 & 0.5921 & -1.6122 & 0.0528 \\
Competition for readers $\left(\beta_{g} / \beta\right)$ & -0.6728 & 0.2487 & -0.4484 & 0.3151 \\
Advertisers value readers $\left(\rho_{g} / \rho\right)$ & -0.9231 & 0.0078 & 1.6044 & 0.0184 \\
Competition for advertisers $\left(\eta_{g} / \eta\right)$ & -0.2250 & 0.4964 & -1.4051 & 0.0071 \\
\hline
\end{tabular}

Note: Coefficient estimates with subscript $g$ denote deviations of a particular parameter from the average coefficient values for all magazines when considering just group $g$. More details are provided in the text.

Table 6: Multihoming percentages for readers

\begin{tabular}{lcccccccc} 
& & & & & & & & \\
Average \\
share \\
Group & 1997 & 1998 & 1999 & 2000 & 2001 & 2002 & 2003 & multireader \\
\hline Health & 3.56 & n.a. & n.a. & n.a. & n.a. & n.a. & n.a. & 3.56 \\
Entertaining & 2.64 & 3.53 & 3.55 & 5.04 & 6.23 & 5.73 & 5.54 & 4.61 \\
Photo & n.a. & n.a. & n.a. & n.a. & n.a. & n.a. & n.a. & n.a. \\
Do-it-yourself & 11.08 & 11.98 & 11.11 & 7.81 & 10.47 & 9.25 & 7.49 & 9.88 \\
Food & 6.38 & 5.82 & 5.53 & 4.29 & 6.66 & 5.21 & 3.88 & 5.40 \\
Gardening & 4.43 & 6.16 & 5.35 & 5.12 & 5.35 & 5.20 & 3.45 & 5.01 \\
Monthly high priced women's & 6.38 & 6.78 & 5.80 & 6.38 & 5.21 & 6.56 & 4.86 & 6.00 \\
Weekly counselling women's & 11.40 & 11.73 & 10.73 & 11.11 & 11.62 & 9.65 & 8.48 & 10.67 \\
PC & 16.53 & n.a. & n.a. & n.a. & n.a. & 9.49 & 11.50 & 12.51 \\
\hline \hline
\end{tabular}

